\title{
Erased: The impact of FOSTA-SESTA and the removal of Backpage on sex workers
}

\author{
Danielle Blunt and Ariel Wolf
}

Please cite this article as: D Blunt and A Wolf, 'Erased: The impact of FOSTASESTA and the removal of Backpage on sex workers', Anti-Trafficking Review, issue 14, 2020, pp. 117-121, https://doi.org/10.14197/atr.201220148

A few days after Backpage was shut down by US federal authorities in April 2018, Public Law 115-164, better known as FOSTA-SESTA, became US law. Its stated goal was to reduce human trafficking by amending Section 230 of the Communications Decency Act and holding Internet platforms accountable for the content their users post. What the law has actually done is put increased pressure on Internet platforms to censor their users. While the law has been lauded by its supporters, the communities that it directly impacts claim that it has increased their exposure to violence and left those who rely on sex work as their primary form of income without many of the tools they had used to keep themselves safe.

In order to better understand the impacts of losing Backpage and the passage of FOSTA-SESTA on sex workers, Hacking//Hustling undertook a participatory action-based, sex worker-led research to collect quantitative and qualitative data from sex worker online communities through an online survey. Over the period of one month, we received 98 responses from this initial outreach. As this round of data collection was conducted via an online survey, the results reflect the experiences of sex workers who still have access to the Internet (including social media platforms) and are thus not representative of all sex workers. We then partnered with Whose Corner is it Anyway (WCIIA), an organisation in western Massachusetts of drug-using, low-income, survival-based, and/or street-based sex workers that provides mutual aid, harm reduction, and political education to its members. WCIIA assisted us in adapting the survey to better fit the experiences of its members. This survey was then distributed to 38 street-based sex workers.

Two-thirds of the respondents to the online survey identified as female, almost one-third as trans/non-binary/gender fluid, and around 3 per cent identified as male. Gender identification was left open-ended, so it is worth noting that trans women may have elected to identify only as female. Three-quarters identified as

This is an open-access article distributed under the terms of the Creative Commons Attribution License (CC-BY). Under the CC-BY license, the public is free to share, adapt, and make commercial use of the work. Users must always give proper attribution to the authors and the Anti-Trafficking Review. 
LGBTQIA and approximately the same number were based in the United States (other locations included Canada, Australia, Europe, and South America). Around two-thirds were white and the rest were mixed-race, black, indigenous/native and Latinx. The most common age group was 25-34. Among the participants in the WCIIA research, the largest share were cis women, white and Latina, and in the age group of $30-39 .^{1}$

As it is difficult to tell what are the effects of the removal of Backpage, implementation of FOSTA-SESTA, the anticipation of its passage, or each platform's pre-existing policies around sex worker content, the questions were framed as 'before/after April 2018'. This short paper presents some of the main findings of the research.

\section{FOSTA-SESTA in Sex Workers' Own Words}

We asked sex workers to define, in their own words, how they understood FOSTASESTA. Many said it was an overbearing, paternalistic law that does nothing to actually fight sex trafficking but, instead, is used to censor sex worker presence online and create more dangerous situations. Many respondents saw this as an extension of the prohibitionist anti-trafficking movement's attempt to eradicate all forms of sex work with no regard for the safety of the people doing it. One sex worker described it as: 'Making online platforms used by sex workers responsible for "sex trafficking" that happens on their site, leading to the shutting down of important online sites used for safety and information.' Another commented, 'It was written to remind whores that our lives are dispensable, we are not protected, our work is unseen and irrelevant, to destabilize our ability to live with any degree of agency, to flaunt the murders and negligent deaths of our loved ones as a daily reminder that the world does not mind at all watching us die and forgetting our names.'

\section{Effects of FOSTA-SESTA}

\section{Income}

The ability to work independently online had reduced the need for sex workers in dire financial situations to work on the streets or through an exploitative agency or third party. Not only did working online previously allow sex workers to

1 For more information on the methodology, profile of the participants and the complete research findings, see: D Blunt and A Wolf, Erased: The impact of FOSTA-SESTA \& the removal of Backpage, Hacking Hustling, New York, 2020, https://hackinghustling. org/erased-the-impact-of-fosta-sesta-2020. 
mitigate harms, it provided some degree of financial security. After FOSTA-SESTA passed, most online respondents reported feeling less safe and financially secure. For most of the online respondents (78.57 per cent), sex work was the main source of income, and for almost half ( 46.94 per cent) it provided the only income. Almost three-quarters (73.5 per cent) reported that their financial situation had changed since April 2018 and that they are now facing increased economic instability ( 72.5 per cent). Only a minority ( 8.16 per cent) said they were financially secure, while the rest said they had income coming in but were generally stressed about their financial situation. Almost a quarter (23 per cent) said they were financially insecure and did not know where their next income was coming from. Almost half ( 45.74 per cent) said they could not afford to advertise their services online anymore, while a large majority (80.61 per cent) said they faced difficulties advertising.

\section{Harm Reduction}

Sex workers are concerned about their health and safety. Digital security practices are a form of harm reduction and many sex workers adopt online digital security methods to stay safer. Of those who utilised web-based harm reduction techniques, the most common tools used were sites dedicated to reviewing clients in order to flag clients with a history of violence, non-payment, or potential connections to law enforcement. Commonly known as 'bad-date lists', sites such as these can fall within the vague parameters of what FOSTA-SESTA criminalises. Another tool used by sex workers is a system of verification in which a new client gives the contact information of past providers to vouch for themselves. VerifyHim is just one example of the harm reduction tools that have been taken down after FOSTASESTA passed.

\section{Community}

Access to the Internet has been shown to improve mental health outcomes in marginalised and criminalised communities. ${ }^{2}$ The Internet provided a space for sex workers to share resources, build community, and advertise their services. Sex workers who use social media to connect with community or share harm-reduction practices may now find themselves isolated from their trusted networks and unable to find community members through regular searches.

2 M Lucassen et al., 'How LGBT+ Young People Use the Internet in Relation to Their Mental Health and Envisage the Use of e-Therapy: Exploratory study', JMIR Serious Games, vol. 6, issue 4, 2018, https://doi.org/10.2196/11249; R Cserni and I Talmud, 'To Know that you are Not Alone: The effect of Internet usage on LGBT youth's social capital', Communication and Information Technologies Annual (Studies in Media and Communications), vol. 9, 2015, pp. 161-182, https://doi.org/10.1108/S2050206020150000009007. 
Asked about the importance of having an online community, one sex worker said, 'Access to support groups and safety groups ... are essential for my screening and networking with others. I like to also keep up to date with what's happening in the sex workers rights movement across the globe and Twitter has been great for that. I follow a lot of outreach organizations and activists.' Another one added, 'Everything I know about being safe in sex work is because I was able to speak to other sex workers online.'

A majority (70 per cent) of online respondents reported a noticeable difference in how they access sex worker communities online since April 2018. Unsure over what is safe to post, many sex workers reported a general sense of fear and paranoia around the consequences of their internet presence. The vagueness of FOSTASESTA, and what qualifies as the facilitation of human trafficking has left sex workers unable to assess the severity of the legal action that could be taken against them. At the same time, it seemed that FOSTA-SESTA has increased some sex workers' engagement in rights activism: half of online respondents said that their involvement in sex worker community had increased since the law was passed, with some stating that they are more determined than ever to seek out people with similar experiences in order to protect themselves. As one worker described, '[While] the accessibility might not be there, my need to take the initiative and make those connections sure has [increased].'

\section{Financial Technologies}

The inaccessibility of financial technologies acts to further the income precarityof people who are pushed off platforms for vague violations of terms of service, people who lack financial or technological literacy, and people who may never have had access to these technologies to begin with. When an online sex worker is kicked off a financial or social platform, they are at risk of losing their means of making money and risk losing access to the community. The lack of access to these technologies also creates a barrier between sex workers and non-sex workers when the most recent technological innovations are not equitably accessible. ${ }^{3}$

One sex worker shared, '(I was kicked off) PayPal, years ago, around 2015. A client put my work email in the memo! Idiot! I was kicked off and could never retrieve the $\$ 500$ balance. I'm lucky-they've stolen thousands from other women.'

Almost three quarters (72 per cent) of online respondents reported using financial technologies in their sex work and a third (33 per cent) said they had been kicked off a payment processor. The majority (78 per cent) of WCIIA respondents

3 A Lake and L Roux, 'Platforms Which Discriminate Against Sex Workers', Survivors against SESTA, 2018, retrieved 2 March 2020, https://survivorsagainstsesta.org/ platforms-discriminate-against-sex-workers. 
reported not having access to a bank account and only 10 per cent reported ever receiving payment from sex work through an online payment processor.

\section{Conclusion}

Comparing our initial data of online workers with that of WCIIA demonstrates that sex workers who are already heavily policed on the streets do not feel the same immediate effects of FOSTA-SESTA and the removal of Backpage. However, for online workers, the removal of Backpage and FOSTA-SESTA has had detrimental effects on their financial stability, safety, access to community, and health outcomes.

There is no evidence that FOSTA-SESTA has curbed trafficking. Instead, our research suggests the opposite: that it has created an environment where marginalised populations are pushed into increased financial insecurity, which, in turn, makes them more vulnerable to labour exploitation and trafficking in the sex industry. Just as sex workers had warned, ${ }^{4}$ our research shows that FOSTASESTA and the removal of Backpage has increased sex workers' exposure to violence while doing nothing to combat trafficking.

FOSTA-SESTA is just one example of the ways in which sex workers are denied equitable access to technologies. This restriction and the ubiquitous surveillance contribute to the harm and marginalisation that sex workers already experience. Legislation like FOSTA-SESTA should be seen in context, in an ongoing history of laws and regulations that utilise technology and public-private partnerships to police women and marginalised communities.

Danielle Blunt is a New York City-based Dominatrix, a full-spectrum doula, and a sex worker rights activist. She recently received her Master's degree in Public Health. Her research investigates the intersection of public health, sex work, and equitable access to technology in marginalised communities. Email: DanielleBlunt@protonmail.ch

Ariel Wolf is a writer, researcher, and former sex worker from New York City. She previously served as the community organiser for the Red Umbrella Project, a non-profit organisation that amplified the voices of those in the sex trades, and as a research assistant for the Center for Court Innovation, where she worked on studies on sex work, human trafficking, gun violence, and procedural justice. Email: ArielHWolf@gmail.com

4 S Cole, 'Pimps Are Preying on Sex Workers Pushed Off the Web Because of FOSTA-SESTA', Vice, 1 May 2018, https://motherboard.vice.com/en_us/article/ bjpqvz/fosta-sesta-sex-work-and-trafficking. 